\title{
Are Gynaecologists underutilising the open access technique for laparoscopic surgery?
}

\section{Atmajit Singh Dhillon, Sandeep Sood*}

Department of Obstetrics and Gynecology, Command Hospital, Lucknow, Uttar Pradesh, India

Received: 15 February 2018

Accepted: 09 March 2018

\section{*Correspondence:}

Dr. Sandeep Sood,

E-mail: sandeepsood100@gmail.com

Copyright: () the author(s), publisher and licensee Medip Academy. This is an open-access article distributed under the terms of the Creative Commons Attribution Non-Commercial License, which permits unrestricted non-commercial use, distribution, and reproduction in any medium, provided the original work is properly cited.

\begin{abstract}
Background: Open access technique for laparoscopic surgery is used by the surgeons routinely, for gaining intraabdominal access safely, but is somehow underutilised by gynaecologists. The most important and dangerous part of laparoscopic surgery is while gaining access to the abdominal cavity, especially in the obese, thin and in patients with previous abdominal scars. Various access techniques have been described including Hasson and Fielding technique, transvaginal or transuterine insufflation, alternative sites for introducing Veress needle abdominally and insufflations with an optical trocar. Open access technique can minimize visceral and vascular injuries and ensures quick and easy intra-abdominal access.

Methods: 250 patients were taken up for laparoscopic surgery at tertiary care service hospitals for open access technique for laparoscopic surgery for a variety of indications. The spectrum of patients ranged from thin, obese, single and multiple transverse scars

Results: A total of 250 patients, were taken up for laparoscopic surgery with the open access method successfully. The median age of the patients was 32 years, there were 77 patients (31\%), with previous transverse laparotomy incisions. Median time for access was 100 seconds, and in 102 patients, there was prolonged access time ranging from 150-300 seconds, 37 (36\%) of these patients were those with previous multiple transverse laparotomies and 65 (64\%), patients were obese. There were no intra-abdominal organ or vascular injuries. Skin incisions healed well.

Conclusions: This study describes the open access technique in patients, with transverse laparotomy scars and especially useful in thin and obese women, and where the chances of vascular and visceral injuries can be high while gaining intra - abdominal access. It is safe, effective, easy to learn and requires minimal instrumentation and can be used in the vast majority of the gynaecological cases.
\end{abstract}

Keywords: Laparoscopic technique, Open access

\section{INTRODUCTION}

The most important and dangerous part of laparoscopic surgery is while gaining access to the abdominal cavity and creating pneumoperitoneum. ${ }^{1}$ The Veress needle technique for creating pneumoperitoneum in laparoscopic surgery is used worldwide but is known for slow insufflation rates and potentially life-threatening complications. $^{2}$ Bleeding from the skin, subcutaneous emphysema, gastrointestinal tract perforation, and minor and major vascular injury are the potential complications associated with abdominal access and creation of pneumoperitoneum, which may not be evident during the procedure and present later with significant morbidity and requiring institution of corrective measures, resulting in readmission and prolonged hospitalization of the patient as well as expensive legal liability for the surgeon as well as the hospital., ${ }^{3,4}$ Open access technique 
especially in the young, thin, obese and in patients with previous abdominal scars, and can minimize or obviate visceral and vascular injuries as the access is under visualization without insertion of any sharp instrument and thereafter only the blunt sleeve is introduced directly without the use of the sharp trocar. Current trend favours a leaning towards open access method, especially in the patient categories mentioned above, to reduce the risks of major complications. ${ }^{5}$

\begin{abstract}
METHODS
250 patients with and without transverse laparotomy scars, thin as well as obese patients were taken up for laparoscopic surgery with indications ranging from diagnostic laparoscopy, operative laparoscopy for subfertility, ectopic pregnancy, ovarian tumours, ovarian cystectomies, chronic pelvic pain, laparoscopic sterilization, total laparoscopic hysterectomy (TLH) and laparoscopic assisted vaginal hysterectomy (LAVH).
\end{abstract}

Table 1: Patients profile for open access technique.

\begin{tabular}{|lllll|}
\hline Number of patients & Mean age in years & Body profile & $\begin{array}{l}\text { Previous laparotomy } \\
\text { incision }\end{array}$ & $\begin{array}{l}\text { Mean access time } \\
\text { (seconds) }\end{array}$ \\
\hline 29 & 28 & Thin & 13 & 50 \\
\hline 99 & 30 & Normal & 29 & 72 \\
\hline 80 & 34 & Overweight & 21 & 126 \\
\hline 42 & 38 & Obese & 14 & 148 \\
\hline
\end{tabular}

The open access technique was used in elective as well as emergency cases. The profile of the patients for open access technique is as shown in Table 1.

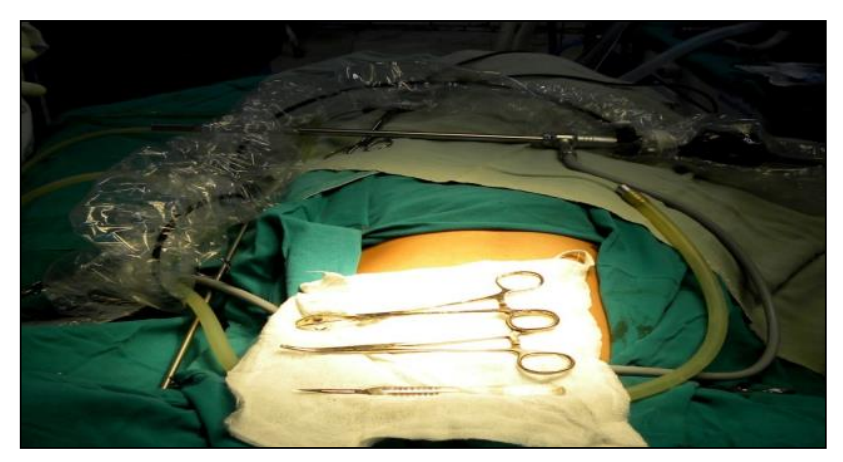

Figure 1: Instruments set up for open access technique.

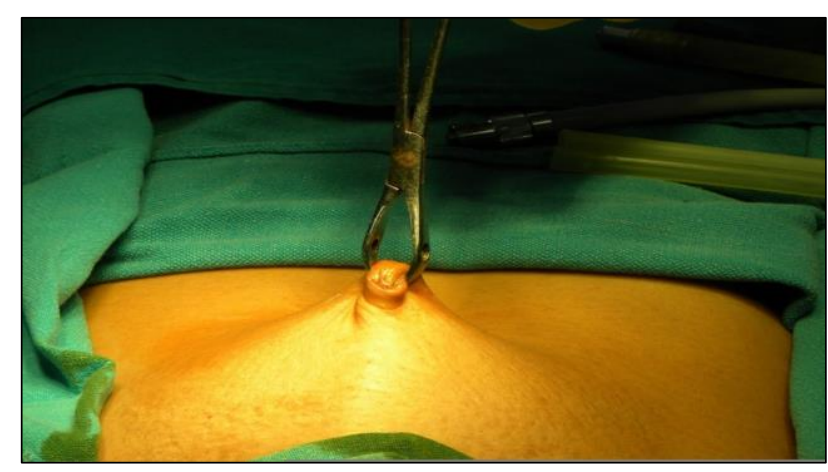

Figure 2: Upward traction of umbilicus with Lanes forceps.

The open access method is a relatively simple method, but great care has to be exercised neverthelessat each step of the procedure as described. Minimal instruments are required for the open access technique. knife and blade, hemostat, and a Lane tissue holding forceps (Figure 1).

The incision in the abdomen can be made either in the supra umbilical, intra umbilical or sub umbilical site, depending upon the patient's body type, thin or obese patient, shape of the umbilicus or the distance from the incision to the area of interest, the nature, type and dimensions of pelvic pathology. Though the technique is relatively safer, great care has to be exercised while making the skin as well as the fascial incision, till the peritoneum is reached and the peritoneum is then very gently and under direct vision opened and intraabdominal access gained. Adequate traction and retraction with small retractors is of great assistance during the procedure. A towel clip/Lane's forceps is applied in the centre, or the upper edge of the umbilicus with upward traction as shown below (Figure 2).

The assistant applies upward and downward traction to put the tissues on stretch and delineate the area where the skin incision can be made (Figure 3).

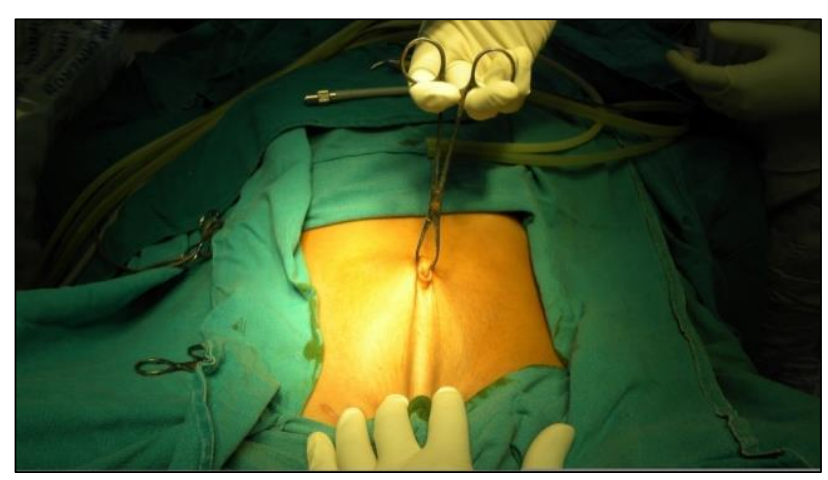

Figure 3: Upward and downward traction by assistant. 
A transverse incision of a length corresponding to the diameter of the trocar is made just below the umbilical fold, where there'll be a slight dimpling of the skin as shown in the figure below (Figure 4).

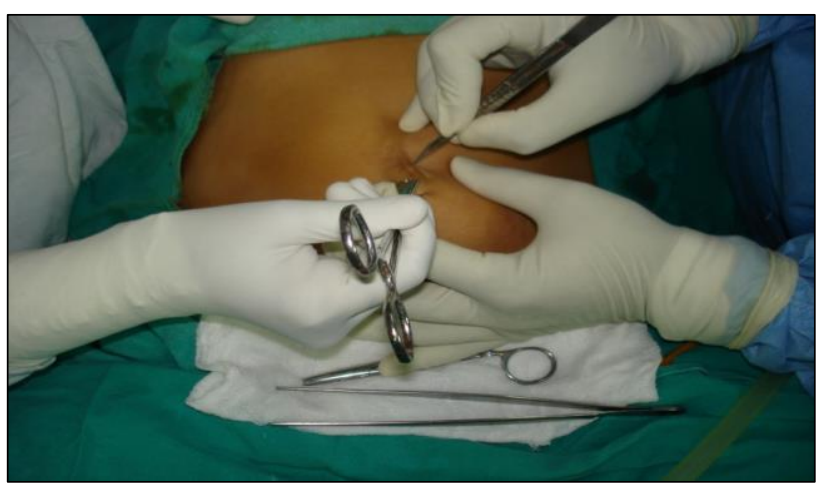

Figure 4: Upward traction of umbilicus with Lanes forceps by assistant and transverse incision infraumblically being made by surgeon.

Incision can be made infraumbilically and the opening can be stretched by a haemostat as shown (Figure 5).

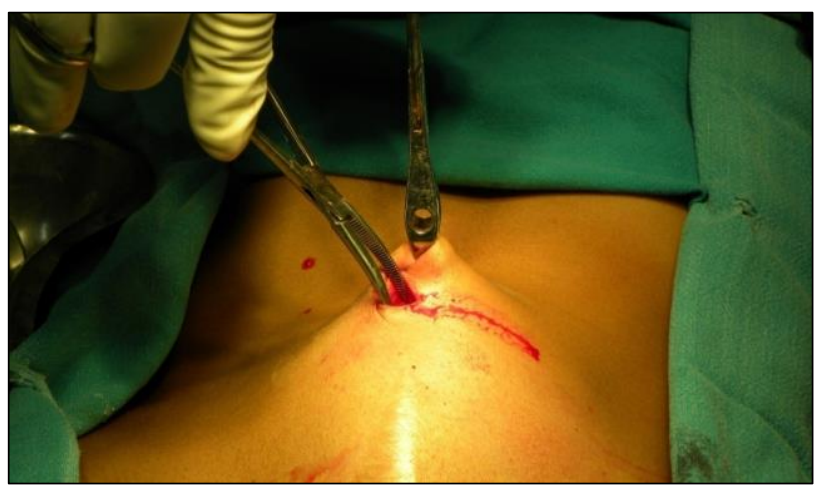

Figure 5: Skin incision being enlarged by hemostat.

The incision can also be made through the umbilicus or alternatively the incision can also be made supraumbilically. The umbilical tube is then exposed after blunt dissection using a haemostat as shown below . In obese patients, two S-shaped retractors or two small skin retractors can be used for exposure of the umbilical tube, after initial dissection. A transverse, or midline incision of appropriate length is made in the umbilical tube with care taken to incise the fascial layer only as depicted below (Figure 6).

The peritoneum is opened bluntly, and the negative pressure allows air to flow into the abdominal cavity and thus creates a distance between the peritoneum and the intestines by steady upward traction of the incision site. The peritoneum is opened bluntly. The peritoneum opening is clearly seen (Figure 7).

Finally, a blunt $10 \mathrm{~mm}$ reusable trochar sleeve, without the introducer is placed through the incision into the abdominal cavity as shown below. Only trocar sleeve being introduced (Figure 8).

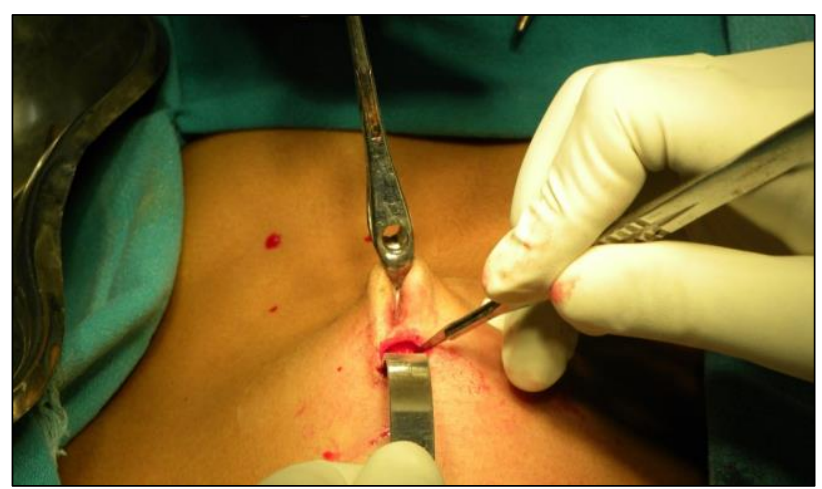

Figure 6: Fascial incision being incised, while traction maintained, and skin retracted with small skin retractor.

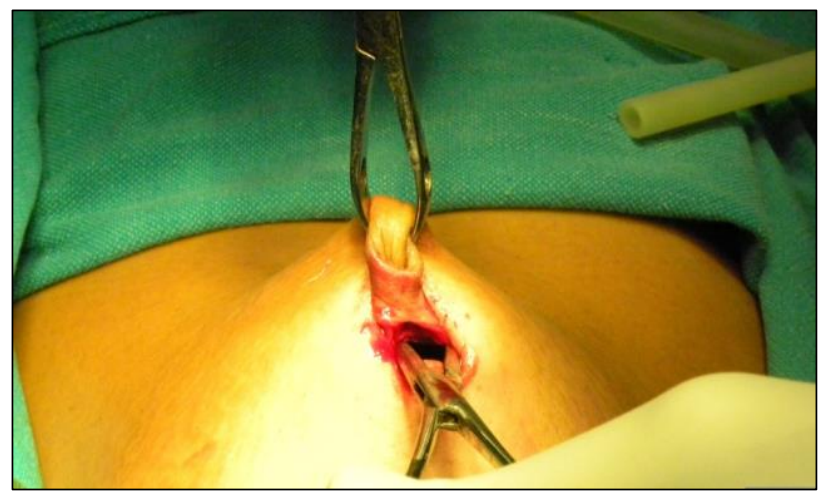

Figure 7: Peritoneal opening being shown after being opened bluntly.

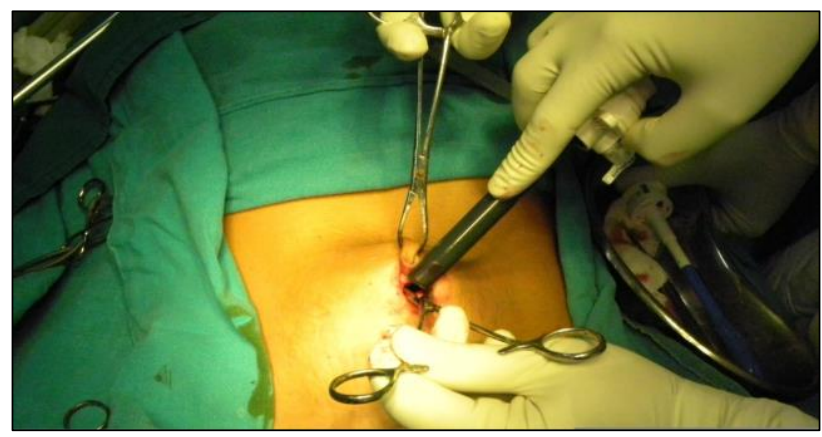

Figure 8: Trocar sleeve without trocar being introduced through the peritoneal opening.

This is followed by insertion of the telescope along with the camera. At the end of the procedure, the fascial layer is exposed and closed with absorbable suture, followed by an intra-cutaneous suture.

\section{RESULTS}

A total of 250 patients, were taken up for laparoscopic surgery with the open access method successfully. The 
open access technique was used in elective cases 182 patients $(73 \%)$ as well as $68(27 \%)$ patients emergency cases. The median age of the patients was 33 years. 29
(11\%) patients were of thin build, $99(40 \%)$ were of normal body type, $80(32 \%)$ were overweight and 42 $(17 \%)$ were obese.

Table 2: Clinical outcomes in patients with open access technique.

\begin{tabular}{|ll|lll}
$\begin{array}{l}\text { Number of } \\
\text { patients }\end{array}$ & $\begin{array}{l}\text { Elective } \\
\text { cases }\end{array}$ & $\begin{array}{l}\text { Emergency } \\
\text { cases }\end{array}$ & $\begin{array}{l}\text { Vascular or } \\
\text { visceral complications }\end{array}$ & Skin incision \\
\hline 250 & 182 & 68 & Nil & Healed well \\
\hline
\end{tabular}

There were 77 patients (31\%), with previous transverse laparotomy incisions. Mean access time was 50 seconds in the thin patients to 148 seconds in the obese patients . A towel clip was applied to the skin adjacent to the trocar in $53(21 \%)$, patients, in whom gas leakage occurred. There were no intra-abdominal organ or vascular injuries. Skin incisions healed well.

\section{DISCUSSION}

Veress needle, followed by blind trocar insertion or direct trocar insertion without creating pneumoperitoneum are the most common approaches for abdominal access during laparoscopic surgery. ${ }^{1,2}$ Bleeding, subcutaneous emphysema, gastrointestinal tract perforation, and minor and major vascular injury are the potential complications associated with abdominal access and creation of pneumoperitoneum. ${ }^{3}$ Complications during laparoscopy are mostly while trying to gain intraabdominal acess and can have disastrous consequences for the patient and grave medical liability for the surgeon and the hospital. ${ }^{4}$

Hasson introduced the open technique, but it didn't become widely acceptable because it required a minilaparotomy, especially difficult in obese patients, as special cone-shaped trochar in order to minimize gas leakage. Modifications of Hasson technique were used without special equipment, but gas leakage and prolonged access time,restricted their usage. ${ }^{6}$ Open access technique through the umbilical tube is commonly used by surgeons, but somehow has been under-utilized by the gynaecologists. ${ }^{7}$ It requires readily available instruments, and in obese patients two S-shaped retractors or two small skin retractors may be used. ${ }^{8}$

It is simple,s afe and easy to learn, provides reasonably quick and safe access into the abdominal cavity is especially useful in young patient with good abdominal wall tone where the lifting up of the abdominal wall while gaining intra-abdominal access with Verees needle or the direct trocar entry is limited, thin and obese patients in whom there is greater chances of intraabdominal organ and vascular injury, but should be used with great care and caution. Current trends lean more towards open access as a measure to reduce the risks of major complications.

\section{CONCLUSION}

Open access technique is especially applicable in patients with transverse laparotomy incisions and is particularly useful in the thin, obese women and in young patients in whom great care has to be taken while gaining intraabdominal access. Open access technique for laparoscopy is simple, safe, easy and effective. This technique can be used with minimal instrumentation and routinely used for majority of the gynaecological laparoscopic surgeries. For laparoscopic surgeons, especially in the early learning curve period, it is useful to have an exposure to the open access method for obtaining a safe access during laparoscopic surgery in difficult cases

Funding: No funding sources

Conflict of interest: None declared

Ethical approval: The study was approved by the Institutional Ethics Committee

\section{REFERENCES}

1. Agresta F, DeSimon P, Ciardo LF, Bedin N. Direct trocar insertion vs Veress needle in nonobese patients undergoing laparoscopic procedures. Surg Endosc. 2004; 18:1778-81 .

2. Schafer M, Lauper M, Krahenbuhl L. Trocar and Veress needle injuries during laparoscopy. Surg Endosc. 2001;15:275-80.

3. Molloy D, Kaloo PD, Cooper M, Nguyen TV. Laparoscopy entry: a literature review and analysis of techniques and complications port entry. Aust N Z J Obstet Gynaecol. 2002;42:246-55.

4. Wind J, Cremers JEL, van Berge Henegouwen MI, Gouma DJ, Jansen FW, Bemelman WA. Medical liability insurance claims on entry-related complications in laparoscopy. Surg Endosc. 2007;21:2094-9.

5. Merlin TL, Hiller JE, Maddern GJ, Jamieson GG, Brown AR, Kolbe A. Systematic review of the safety and effectiveness of methods used to establish pneumoperitoneum in laparoscopic surgery. $\mathrm{Br} \mathbf{J}$ Surg. 2003;90:668-79 .

6. Hasson HM. A modified instrument and method for laparoscopy. Am J Obstet Gynecol. 1971;110:886-7.

7. Bonjer HJ, Hazebroek EJ, Kazemier G, Giuffrida MC, Meijer WS, Lange JF. Open vs closed 
establishment of pneumoperitoneum in laparoscopic surgery. Br J Surg. 1997;84:599-602.

8. Pawanindra L, Sharma R, Chander J, Ramteke VK. A technique for open trocar placement in laparoscopic surgery using the umbilical cicatrix tube. Surg Endosc. 2002;16:1366-70 .

9. Hurd WW, Randolph JF, Holmberg RA, Pearl ML, Hubbell GP. Open laparoscopy without special instruments or sutures, comparison with a closed technique. J Reprod Med. 1994;39:393-7.

Cite this article as: Dhillon AS, Sood S. Are Gynaecologists underutilising the open access technique for laparoscopic surgery?. Int J Reprod Contracept Obstet Gynecol 2018;7:1791-5. 